\title{
GCU
}

Glasgow Caledonian

University

University for the Common Good

\section{Feasibility study on application of microwave radiometry to monitor contamination level on insulator materials}

Jiang, Y.; McMeekin, S.G.; Reid, A.J.; Nekahi, A.; Judd, M.D.; Wilson, A.

Published in:

IEEE Transactions on Dielectrics and Electrical Insulation

DOI:

10.1109/TDEI.2015.005269

Publication date:

2016

Document Version

Author accepted manuscript

Link to publication in ResearchOnline

Citation for published version (Harvard):

Jiang, Y, McMeekin, SG, Reid, AJ, Nekahi, A, Judd, MD \& Wilson, A 2016, 'Feasibility study on application of microwave radiometry to monitor contamination level on insulator materials', IEEE Transactions on Dielectrics and Electrical Insulation, vol. 23, no. 2, pp. 1012-1020. https://doi.org/10.1109/TDEl.2015.005269

\section{General rights}

Copyright and moral rights for the publications made accessible in the public portal are retained by the authors and/or other copyright owners and it is a condition of accessing publications that users recognise and abide by the legal requirements associated with these rights.

Take down policy

If you believe that this document breaches copyright please view our takedown policy at https://edshare.gcu.ac.uk/id/eprint/5179 for details

of how to contact us. 


\title{
Feasibility Study on Application of Microwave Radiometry to Monitor Contamination Level on Insulator Materials
}

\author{
Y. Jiang, S. G. McMeekin, A. J. Reid, A. Nekahi \\ Glasgow Caledonian University \\ School of Engineering and Built Environment \\ Glasgow, G4 0BA, United Kingdom \\ M. D. Judd \\ High Frequency Diagnostics and Engineering Ltd \\ Glasgow, G3 7JT, United Kingdom \\ and $\mathbf{A}$. Wilson \\ Doble PowerTest Ltd \\ Surrey, GU3 1NA United Kingdom
}

\begin{abstract}
This paper introduces a novel method for monitoring contamination levels on high voltage insulators based on microwave radiometry. Present contamination monitoring solutions for high voltage insulators are only effective in predicting flashover risk when the contamination layer has been wetted by rain, fog or condensation. The challenge comes where the pollution occurs during a dry period prior to a weather change. Under these conditions, flashover can often occur within a short time period after wetting and is not predicted by measurements taken in the dry period. The microwave radiometer system described in this paper measures energy emitted from the contamination layer and could provide a safe, reliable, contactless monitoring method that is effective under dry conditions. The relationship between equivalent salt deposit density and radiometer output is described using a theoretical model and experimentally verified using a specially designed $X$-band radiometer. Results demonstrate that the output from the radiometer is able to clearly distinguish between different levels of contamination on insulator materials under dry conditions. This novel contamination monitoring method could potentially provide advance warning of the future failure of wet insulators in climates where insulators can experience dry conditions for extended periods.
\end{abstract}

Index Terms - Insulators, microwave radiometry, insulator contamination, pollution measurement.

\section{INTRODUCTION}

HIGH voltage insulators form an essential part of high voltage electric power transmission systems. Outdoor insulators are subjected to various harsh operating conditions and environments. Insulators located near coastal regions encounter sodium chloride $(\mathrm{NaCl})$ in the form of sea water while those located in inland areas may be contaminated by road salt and industrial pollutants such as paper pulp, fly-ash, cement dust, etc [1-3]. Contamination on the surface of the insulators enhances the chances of flashover. Flashover is one of the most common causes of failure of $\mathrm{HV}$ insulators resulting in the loss of power supply and an increase in the associated engineering and maintenance costs. The term Equivalent Salt Deposit Density (ESDD) is used to indicate the
$\mathrm{NaCl}$ per unit surface area $\left(\mathrm{cm}^{2}\right)$ of the insulator [4]. In dry conditions contamination is usually less of a concern due to its low conductivity and, therefore, low risk of flashover [5]. However in wet conditions, i.e. in the presence of rain, snow, fog or dew, the contaminants dissolve to form a conductive layer on the insulator surface, initiating leakage current and partial discharge (PD) activity, which can ultimately lead to flashover [6-8].

Direct measurements of contamination levels on energized insulators are difficult to obtain, especially under dry conditions. A standard method given by IEC 60815 to determine the contamination level is to measure the ESDD by cleaning the insulator in a specific volume of water and then measuring the conductivity of the solution [9]. However, this method requires the insulator to be taken off-line. On-line 
contamination monitoring systems in operation are mainly based on leakage current (LC) and PD [10, 11]. One standard technique to monitor LC and PD on HV insulators employs a current transformer (CT) or a shunt resistor installed in series with the grounding lead from the insulator. In some cases, an electrode ring is fixed around insulator to intercept the leakage current before it reaches the ground terminal of the insulator [12]. Conventional LC and PD monitoring systems have two main drawbacks:

a. The ring sensor somewhat reduces the creepage distance of the insulator and insulation security due to the requirement for direct contact with insulator. A CT or a resistor might require disturbing the earth lead.

b. Both LC and PD measurement systems are only effective when the contamination layer has been wetted by rain, fog or condensation; under these conditions flashover might occur before there is time to implement remedial measures such as cleaning [13].

This paper presents a novel monitoring method based on microwave radiometry that enables the contamination of an energized HV insulator to be determined under dry conditions. Microwave radiometry is one of the basic techniques for measuring electromagnetic radiation and has been widely used in astronomy, meteorology, oceanography, geography and hydrology [14]. Electromagnetic radiation of a material will cover a very wide frequency band with the spectrum being a function of material's emissivity and temperature. The emissivity of a material represents the relative ability of its surface to emit energy by radiation and is referred to as the brightness temperature (BT) $T_{B}$, defined as the temperature of a blackbody that would radiate the same power [15]. A contaminated insulator emits a different electromagnetic energy level compared to a clean insulator due to the contamination layer. Thus, a radiometer, or passive receiver that detects the input power in a specific frequency band using an antenna, has the ability to monitor pollution level on an insulator surface.

The paper first presents a theoretical model for determining the pollution levels on $\mathrm{HV}$ insulators that has been developed from remote sensing techniques used in the detection of soil salinity. Then the design of an X-band (8.0 to $12.0 \mathrm{GHz}$ ) radiometer with high sensitivity and stability with relatively low cost is described. A laboratory experiment was implemented to verify the consistency between theoretical model and practical radiometer outputs under dry conditions based on artificial polluted insulator material flat slabs. The results 4 show good agreement between the theoretical and experimental results and indicate that this novel monitoring method has the potential to provide advanced warning of flashover on HV insulators due to pollution.

\section{THEORETICAL MODEL}

Microwave radiometers are widely used in remote sensing for soil moisture distribution and work has been published on models to provide the soil salinity from brightness temperature [16-18]. Obtaining the ESDD of a contamination layer can be treatable in a similar manner to the soil salinity detection problem. Soil's brightness temperature is affected by several unknown parameters including moisture, salinity, bulk density, thickness and surface roughness. The contamination layer on an insulator is relatively thin with a smooth surface, therefore the influence of thickness and surface roughness can be ignored when compared to moisture and salinity. The bulk density is calculated based on the properties of the artificial contamination layer described in IEC 60507 [19]. Thus, the only parameters that need to be inferred are moisture and salinity.

Figure 1 shows the structure of the proposed system model relating radiometer output to ESDD. Within this framework, the dielectric mixing model evaluates the dielectric properties of the insulator contamination layer as a function of moisture, salinity, environment temperature and humidity by assuming it as salt and water affected soil. The brightness temperature model describes the relationship between dielectric properties, emissivity and brightness temperature of a contaminated insulator. Finally, the radiometer model converts input power to output voltage and is related to system design.

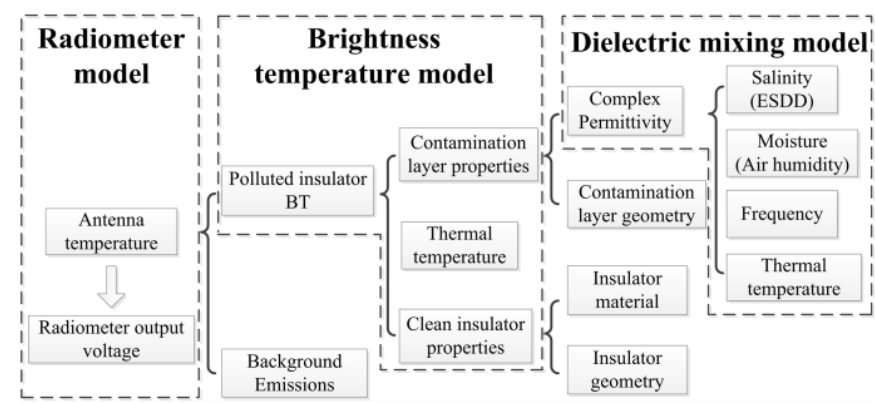

Figure 1. Theoretical model of applying radiometry to monitor insulator contamination.

\subsection{DIELECTRIC MIXING MODEL}

The dielectric mixing model developed by Dobson [20] is a classical model for remotely sensing soil moisture. It gives the dielectric constant of soil as a function of its water content. In consideration of the effect of the salt on the soil, the dielectric mixing model needs to be modified as this model only works under very low salt content. After replacing the dielectric constant model for water with the dielectric constant model of saline water, developed by Stogryn [21], the dielectric mixing model will carry the information of both soil moisture and soil salinity. On the insulator surface, moisture is a function of air humidity which can be easily measured.

In these models, complex permittivity $\varepsilon$ is a complex number $\varepsilon=\varepsilon^{\prime}-j \varepsilon^{\prime \prime}$ with real part $\varepsilon^{\prime}$ and imaginary part $\varepsilon^{\prime \prime}$. The real part $\varepsilon^{\prime}$ is related to the stored energy within the medium and the imaginary part $\varepsilon^{\prime \prime}$ is related to the dissipation (or loss) of energy within the medium. The model will be developed from pure water to saline water and finally to the salt-affected soil which approximates a contamination layer on an insulator surface.

\subsubsection{DIELECTRIC MODEL OF SALINE WATER}


Lane and Saxton modified a Debye-type relaxation to account for the ionic-conductivity losses caused by the salinity of the water [22]. In terms of Stogryn's formulation, the real and imaginary parts of the complex permittivity of saline water are respectively given by [17, 21, 22]:

$$
\left\{\begin{array}{c}
\varepsilon_{S w}^{\prime}=\varepsilon_{S w \infty}+\frac{\varepsilon_{S w 0}-\varepsilon_{S w \infty}}{1+\left(2 \pi f \tau_{S w}\right)^{2}} \\
\varepsilon_{S w}^{\prime \prime}=\frac{2 \pi f \tau_{S w}\left(\varepsilon_{S w 0}-\varepsilon_{S w \infty}\right)}{1+\left(2 \pi f \tau s_{w}\right)^{2}}+\frac{\sigma_{N a C l}}{2 \pi \varepsilon_{0} f}
\end{array}\right.
$$

where $\varepsilon_{s w \infty}=4.9$ is the high frequency limit of $\varepsilon_{s w}^{\prime}$ and $\varepsilon_{0}=8.854 \times 10^{-12}(F / m)$ is the permittivity of free space. Following IEC standard 60507 [19], the saline water in the insulator contamination layer can be represented as $\mathrm{NaCl}$ solution, the conductivity of which is given by Weyl [23] as:

$$
\begin{aligned}
\sigma_{N a C l}(T, N)= & \sigma_{N a C l}(25, N)\left\{1.0-1.9 \times 10^{-2} \Delta+8.1 \times\right. \\
& 10^{-5} \Delta^{2}-\Delta N\left[3 \times 10^{-5}+3.9 \times 10^{-5} \Delta+\right. \\
& \left.\left.N\left(1.7 \times 10^{-5}-6.6 \times 10^{-6} \Delta\right)\right]\right\}
\end{aligned}
$$

where $N$ is the normality of the salt solution and dependent on the salinity, $\Delta=25-T$ and $T$ is the temperature in Kelvin.

\subsubsection{DIELECTRIC MODEL OF SALT AFFECTED SOIL}

Dobson's model in equation (3) below represents the dielectric constant of soil as a function of soil moisture, $m_{v}$, dielectric constant of pure water inside soil, $\varepsilon_{p w}$, permittivity of dry soil, $\varepsilon_{s}$, bulk density of dry soil, $\rho_{s}$ and bulk density of wet soil, $\rho_{b}$.

$$
\left\{\begin{array}{c}
\varepsilon_{m}^{\prime}=\left(1+\left(\rho_{b} / \rho_{s}\right) \varepsilon_{s}^{\alpha}+m_{v}^{\beta^{\prime}} \varepsilon_{p w}^{\prime \alpha}-m_{v}\right)^{\frac{1}{\alpha}} \\
\varepsilon_{m}^{\prime \prime}=\left(m_{v}^{\beta^{\prime \prime}} \cdot \varepsilon_{p w}^{\prime \prime \alpha}\right)^{\frac{1}{\alpha}}
\end{array}\right.
$$

where $\alpha$ and $\beta$ are related to the soil texture. By combining equation (3) with Stogryn's model given in equation (1), the dielectric constant of pure water is replaced with the dielectric constant of saline water where $\varepsilon_{p w}^{\prime}=\varepsilon_{s w}^{\prime}$ and $\varepsilon_{p w}^{\prime \prime}=\varepsilon_{s w}^{\prime \prime}$. In IEC standard 60507 [19], the contamination layer consists entirely of Kaolin, which is a form of clay with a typical bulk density of $\rho_{b}=1 \mathrm{~g} / \mathrm{cm}^{3}$.

For dry soil, Equation (4) gives the relationship between its permittivity $\varepsilon_{s}$ and bulk density $\rho_{s}$ (around $2.66 \mathrm{~g} / \mathrm{cm}^{3}$ ).

$$
\varepsilon_{s}=\left(1.01+0.44 \rho_{s}\right)^{2}-0.062
$$

Figure 2, which is obtained by equation (3), shows the relationship between dielectric constant, soil moisture ( $\mathrm{M}$ in percentage) and soil salinity from the theoretical model. The results are shown at the two protected frequency bands, 1.4 GHz and $10.65 \mathrm{GHz}$, that are typically chosen for microwave radiometer systems operation to avoid interference from radar and communication systems [24]. Figure 2 shows that the dielectric constant is more sensitive to the water content and salinity at $1.4 \mathrm{GHz}$, a typical frequency band used for soil moisture and sea water salinity sensors on satellites [16, 18, 25]. However, the wavelength at $1.4 \mathrm{GHz}$ is $214.2 \mathrm{~mm}$ which is too large to provide a reasonable spatial resolution in relation to size of the insulators under test. An operating frequency of $10.65 \mathrm{GHz}$ $(\lambda=28.2 \mathrm{~mm})$ was therefore chosen to achieve a balance between system sensitivity and spatial resolution.

\subsection{BRIGHTNESS TEMPERATURE MODEL}

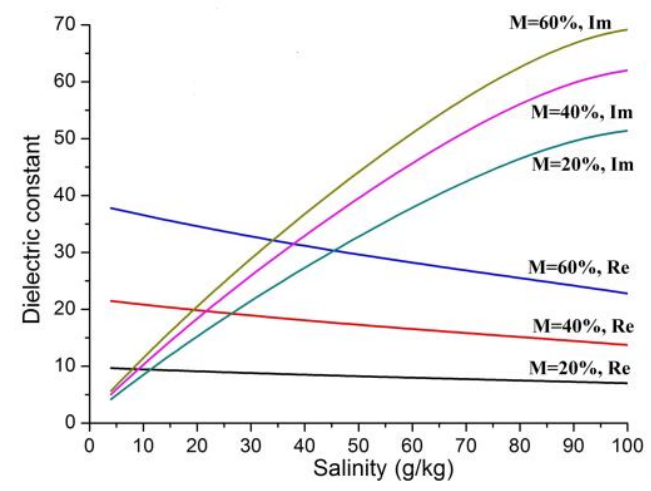

(a) $1.4 \mathrm{GHz}$

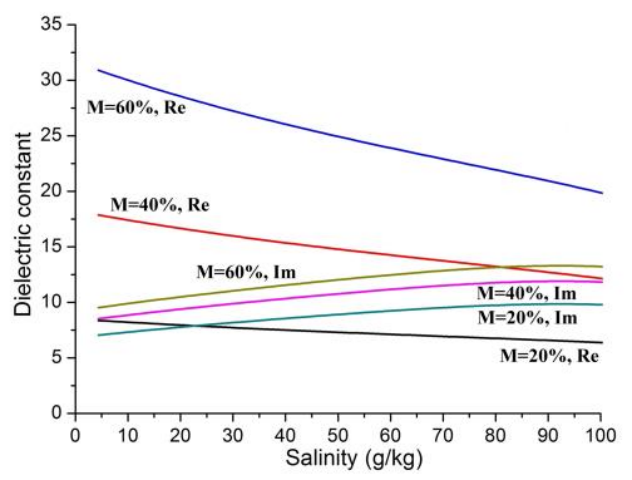

(b) $10.65 \mathrm{GHz}$

Figure 2. Theoretical relationship between dielectric constant, moisture and salinity at (a) $1.4 \mathrm{GHz}$ and (b) $10.65 \mathrm{GHz}$ (note change in scale).

The insulator's radiance can be expressed by its brightness temperature [26]:

$$
T_{B}=\varepsilon T_{o}=(1-R) T_{o}
$$

where $R$ is the Fresnel reflection coefficient on the insulator surface and $T_{o}$ is the temperature in Kelvin of the contaminated insulator. A brightness temperature model is applied to transform the geometry structure of the insulator and dielectric properties to emissivity and finally the brightness temperature of the contaminated insulator.

In a practical environment, the insulator is in the air with a pollution layer on the surface. The surrounding air forms a third layer. We assume that the insulator surface with contamination is a double-layer homogeneous dielectric plate with a smooth surface, as shown in Figure 3. Thus, a double layer model is applied to calculate the brightness

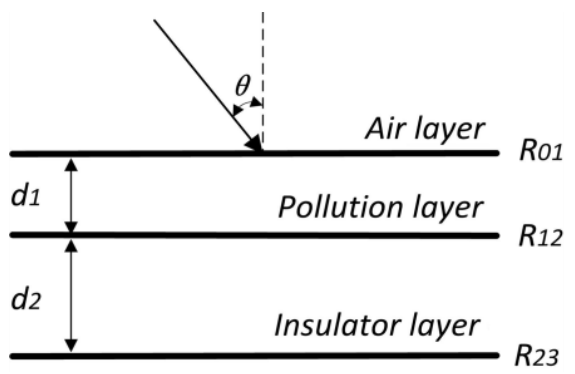

Figure 3. Double dielectric layer model of contaminated insulator surface. 
temperature of the contaminated insulator. [27]:

The reflection coefficient of this double layer is given by

$$
R=\frac{R_{01}+R_{12}^{\prime} \exp \left(-j 2 \delta_{1}\right)}{R_{01} R_{12}^{\prime} \exp \left(-j 2 \delta_{1}\right)+1}
$$

Where

$$
R_{12}^{\prime}=\frac{R_{12}+R_{23} \exp \left(-j 2 \delta_{2}\right)}{R_{12} R_{23} \exp \left(-j 2 \delta_{2}\right)+1}
$$

And

$$
\delta_{i}=\frac{2 \pi d_{i}}{\lambda} \sqrt{\varepsilon_{i}^{2}-\sin ^{2} \theta}
$$

where $\lambda$ is the wavelength in free space, $\varepsilon_{i}$ is the complex permittivity of the $i$-th layer, $d_{i}$ is the thickness of the $i$-th layer and $\theta$ is the angle of incidence. $R_{12}$ is Fresnel's reflection coefficient for the interface between the pollution layer and the insulator layer. $R_{23}$ is the reflection coefficient on the insulator reverse interface. Normally, the values of $R_{12}$ and $R_{23}$ are sensitive to vertical or horizontal polarization. However, the radiation is produced independently by a large number of atoms or molecules whose emissions are uncorrelated and generally of random polarizations. $R_{12}$ and $R_{23}$ are not sensitive to polarization in this case. The angle of incidence $\theta$ keeps zero during both theoretical study and experimental setup.

\subsection{DISSCUSSION}

Figure 4 presents the relationship between salinity, frequency, moisture, angle of incidence and brightness temperature of a flat glass plane with varying levels of contamination. The brightness temperature increases with increasing salinity of the contamination layer at $0^{\circ}$ angle of incidence as shown in Figure 4. The sensitivity of the brightness temperature to salinity is higher at high moisture levels. Therefore, the radiometer will have better sensitivity to detect the ESDD of contaminated insulators under wet conditions than under dry conditions. In the following experiment, the thickness of the pollution layer was varying from $0.3 \mathrm{~mm}$ to $0.7 \mathrm{~mm}$. In this range, the thickness changes the brightness temperature but is much less significant compare to the salinity based on the theoretical model. Thus, the effect of the thickness was ignored in the experiment.

\section{RADIOMETER SYSTEM}

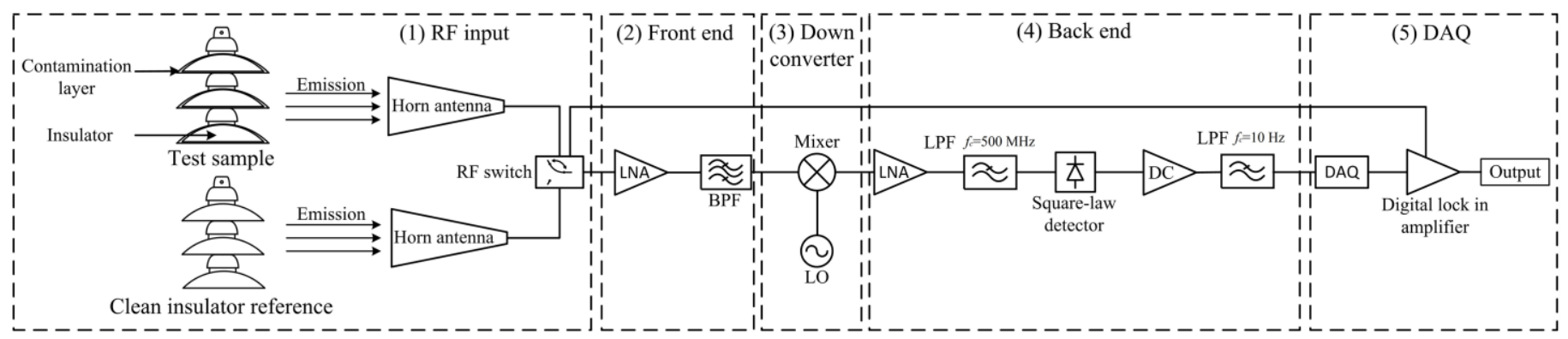

Figure 5. Block diagram of the X-band Dicke radiometer with external reference for monitoring contamination level on insulator surface.
The radiometer system developed for monitoring pollution levels on insulators, shown in Figure 5, is based on a Dicke radiometer with a superheterodyne architecture

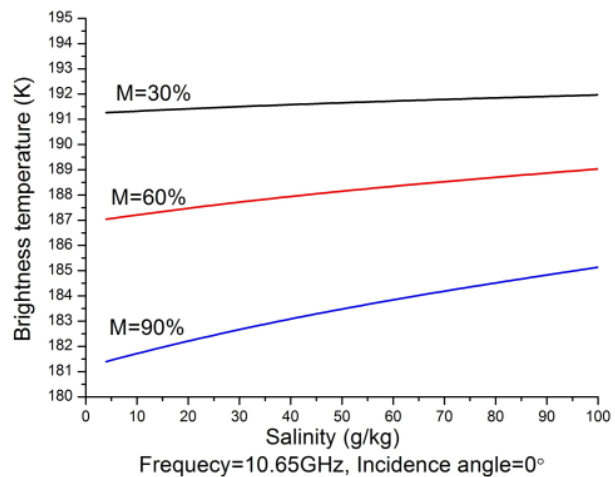

Figure 4. Theoretical relationship between Brightness temperatures and salinity at different moisture level for varying levels of moisture content, M.

[14]. The radiometer system can be divided into five sections: (1) RF input, (2) front-end, (3) downconverter, (4) back-end and (5) data acquisition (DAQ). The RF input signal to the radiometer systems is captured using a horn antenna with $20 \mathrm{~dB}$ gain, pointed towards the insulator sample. The system used in these experiments is a passive receiver with a centre frequency of $10.65 \mathrm{GHz}$ and $1 \mathrm{GHz}$ bandwidth. The output voltage of the radiometer is linearly proportional to the input power at the antenna. The design of the system has focused on optimizing accuracy, stability and sensitivity while using a relatively low cost architecture.

\subsection{RADIOMETER DESIGN}

The RF input module detects the RF emission from the polluted sample under test and an external reference signal from a clean sample. The front-end circuit of the radiometer has two main tasks: selecting the input frequency band by filters and amplifying the RF signal by a low noise amplifier (LNA) prior to the downconverter and the lowfrequency circuit. The superheterodyne circuit downconverts the X-band input signal to a $0-500 \mathrm{MHz}$ signal. The back-end circuit again uses a LNA and a low pass filter to further improve the signal-to-noise ratio before a square-law detector provides a dc output voltage. After further amplifying and filtering, the dc output is captured by a DAQ card and a digital lock-in amplifier synchronised to the switching between the contaminated and reference signals.

\subsection{SYSTEM ANALYSIS}

The classical Dicke radiometer, shown in Figure 6, uses an RF switch to allow continuous comparison between the input power and an internal reference. 


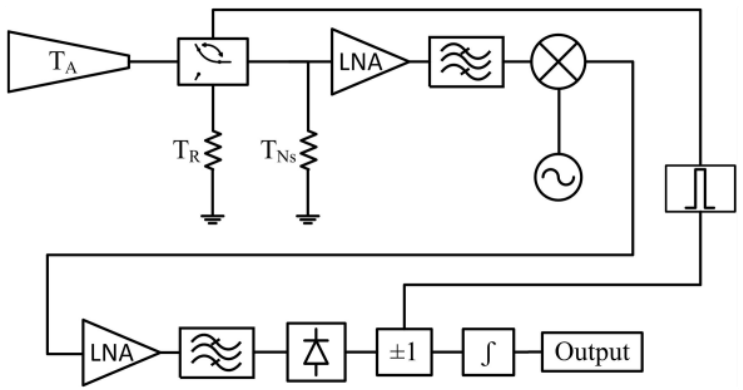

Figure 6. Block diagram of the classical Dicke radiometer with a superheterodyne architecture.

The output of this Dicke radiometer can be expressed as [14]:

$$
\begin{aligned}
V_{\text {out }} & =c\left(T_{A}+T_{N S}\right) G-c\left(T_{R}+T_{N S}\right) G \\
& =c\left(T_{A}-T_{R}\right) G
\end{aligned}
$$

where $c$ is a constant, $G$ is the system gain, $T_{R}$ is the equivalent antenna temperature of the internal reference signal and $T_{N s}$ is the system noise temperature generated by the thermal noise and instabilities of the individual components in the radiometer system. $T_{A}$ is the antenna temperature which relates to the brightness temperature of the sample and background radiation and can be expressed as:

$$
T_{A}=T_{A P}+T_{N P E}
$$

where $T_{A P}$ is the antenna temperature generated by the test sample and $T_{N P E}$ represent the contribution to the antenna temperature due to the background radiation of the surrounding environment of the test sample.

During initial testing of the Dicke radiometer on the insulator samples, the system was found to be very sensitive to external environmental conditions, such as changes in ambient temperature, background light and external RF interference. To address this issue an external reference signal from an antenna pointed at a clean sample was used to replace the internal thermal reference used in the classical Dicke radiometer system. Thus, $T_{R}$ in Equation (9) can be replaced by:

$$
T_{R}=T_{A C}+T_{N C E}
$$

where $T_{A C}$ is the antenna temperature generated by the reference sample and $T_{N C E}$ is the antenna temperature generated by the background radiation of the reference sample. It was important to minimize any difference in the positioning of the samples relative to the antenna to ensure the samples have same experimental conditions, such as surface temperature and background EM noise. After replacing the internal reference of the classic Dicke radiometer with an external reference antenna Equation (9) is modified to:

$$
\begin{gathered}
V_{\text {out }}=c\left(T_{A P}+T_{N S}+T_{N P E}\right) G-c\left(T_{A C}+T_{N S}+T_{N C E}\right) G \\
=c\left(T_{A P}-T_{A C}\right) G+c\left(T_{N P E}-T_{N C E}\right) G
\end{gathered}
$$

Since the polluted and clean samples have similar surrounding environmental conditions, these components will cancel out, allowing Equation (12) to be expressed as:

$$
V_{\text {out }}=c\left(T_{A P}-T_{A C}\right) G
$$

The system output becomes dependent only on the brightness temperature differences between the polluted and clean insulator. The difference in the brightness temperature can be correlated to a change in ESDD levels.

\subsection{RADIOMETER CALIBRATION}

The calibration of a conventional Dicke radiometer uses two RF terminations with different, well-known noise temperatures to replace the antenna at the radiometer input. The relationship between antenna temperature and output voltage can be found from two data sets according to Equation (13). In our system, the external reference does not have a constant noise temperature compared to an internal reference. Thus, the system output voltages of two clean samples with the same material and geometry as the external reference but at different thermal temperatures are recorded to give the system equation:

$$
V_{\text {diff }}=V_{\text {offset }}+0.1021 \cdot T_{\text {diff }}
$$

where $V_{\text {diff }}$ is the output voltage after lock-in amplifier, $V_{\text {offset }}=21.0 \mathrm{mV}$ is the calculated internal voltage difference brought by RF switch and $T_{\text {diff }}$ is the antenna temperature difference between sample and reference.

\section{EXPERIMENT}

\subsection{SAMPLE PREPARATION}

To remove the effect of the complex surface geometry of the HV insulators for the purpose of testing the concept, it was decided to use flat glass and porcelain samples with dimensions of $500 \mathrm{~mm} \times 200 \mathrm{~mm}$ and $8 \mathrm{~mm}$ thick. The solid layer method recommend by IEC standard 60507 was employed to form an artificial pollution layer on the sample surfaces [19]. This method involves uniformly spraying a pollution suspension on the sample surfaces to form a solid layer.

The composition of the suspension used in tests contained $6.5 \mathrm{~g}$ Kaolin, $150 \mathrm{~g}$ water and a suitable amount of $\mathrm{NaCl}$ to control the ESDD level. A $150 \mathrm{ml}$ suspension was sprayed evenly on one sample surface and the sample was then left to dry for 48 hours in a low humidity room. After the test had been completed, the solid layers were washed off with $500 \mathrm{ml}$ distilled water and the ESDD of each sample was obtained by measuring the conductivity of the washing water and then calculated using Equation (15) [8]:

$$
\left\{\begin{array}{c}
E S D D=S_{a} \cdot V / A \\
S_{a}=\left(5.7 \cdot \sigma_{20}\right)^{1.03}
\end{array}\right.
$$

where $S_{a}$ is the salinity, $\sigma_{20}$ is the conductivity of the $\mathrm{NaCl}$ solution corrected to $20{ }^{\circ} \mathrm{C}, V$ is the volume of distilled water and $A$ is the sample surface area.

Six pairs of glass and porcelain samples were tested, each with different contamination levels. Table 1 lists the properties of the contamination layers on these sample pairs.

\subsection{EXPERIMENTAL SETUP}

It is important to insure the external reference and samples under test have the same experimental conditions, such as surface temperature and background EM noise, as differences between $T_{N P E}$ and $T_{N C E}$ will affect the output voltage as given in equation (12). Both samples and 
temperature for the porcelain and glass samples as a function of ESDD on the same scale. From Figure 10 we can calculate the rate of change of the brightness temperature as a function of ESDD levels. The glass samples had a rate of change of approximately 1.25 $\mathrm{K} /\left(\mathrm{mg} / \mathrm{cm}^{2}\right)$ whilst the porcelain samples had a rate of change of only $0.33 \mathrm{~K} /\left(\mathrm{mg} / \mathrm{cm}^{2}\right)$. The difference in the rate of change of the brightness temperature for the glass and porcelain samples can be attributed to the difference in the complex permittivity, $\varepsilon_{i}$, and reflection coefficient, $R$, of the different layers, which will have a strong effect on their brightness temperature as defined in equations (5-8). This indicates that the radiometer will have different efficiencies for detecting contamination level on differing insulator materials.

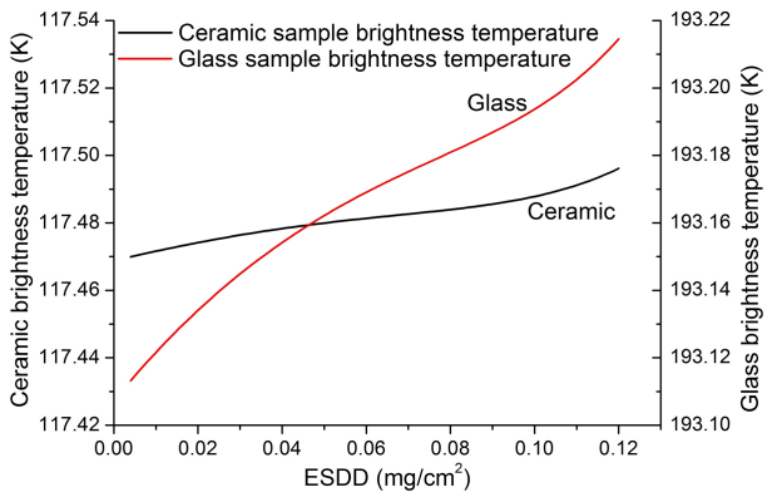

Figure 10. Comparison of the rate of change in the theoretical values of brightness temperature for the ceramic and glass samples as a function of ESDD under the same scales.

\section{CONCLUSION}

This paper has described a theoretical and experimental study into the feasibility of using an X-band radiometer to assess contamination level on HV insulators under dry conditions. The theoretical model employs the principles of remote sensing techniques to evaluate the relationship between the contamination layer equivalent salt deposit density levels, complex dielectric properties and brightness temperature. An X-band radiometer was designed and implemented to measure the radiation from a polluted surface relative to a clean surface. The samples were polluted based on IEC standard 60507. The radiometer system performed about $30 \mathrm{mV}$ difference between polluted and clean samples. The experimental results show good agreements with the theoretical model and validate the proposed method. According to the experimental results, this novel method is effective under dry conditions and has more sensitive response to contamination on glass surface rather than porcelain surface. The work provides a foundation for future investigations into the development of an on-line monitoring system for insulator pollution that is effective under dry conditions. However, to develop a practical system a number of challenges will need to be addressed including improving the system sensitivity and providing an internal reference signal to replace the use of the external clean insulator. A system with active power source is under development to address these problems.

In future, the effects of complex insulator surface geometries and non-soluble salt deposit density will be studied. The system will be also tested for monitoring energized insulators to evaluate the effect of non-uniform electric field around insulator. Because this novel method is strongly influenced by external noise from the surrounding environment, further denoising technology will be studied for the onsite tests.

\section{ACKNOWLEDGMENT}

The authors would like to thank Doble Powertest and the Energy Technology Partnership (ETP) for funding this project.

\section{REFERENCES}

[1] S. Huafeng, J. Zhidong, G. Zhicheng, and L. Licheng, "Mechanism of contaminant accumulation and flashover of insulator in heavily polluted coastal area", IEEE Trans. Dielectr. Electr. Insul, Vol. 17, pp. 1635-1641, 2010.

[2] M. A. R. M. Fernando and S. M. Gubanski, "Ageing of silicone rubber insulators in coastal and inland tropical environment", IEEE Trans. Dielectr. Electr. Insul, Vol. 17, pp. 326-333, 2010.

[3] A. El-Sulaiman and M. Iqbal Qureshi, "Effect of Contamination on the Leakage Current of Inland Desert Insulators", IEEE Trans. Dielectr. Electr. Insul, Vol. 19, pp. 332-339, 1984.

[4] G. Montoya, I. Ramirez, and J. I. Montoya, "Correlation among ESDD, NSDD and leakage current in distribution insulators", Proc. IEE Generation, Transmission and Distribution, Vol. 151, pp. 334340, 2004.

[5] M. A. M.Piah and A. Darus, "Leakage Current Analysis of Polymer Insulating Material with Variable Contaminant Flow Rate", National conf. Australasian Universities Power Engineering , Melbourne, Australia, pp. 1-5, 2002.

[6] S. Venkataraman and R. S. Gorur, "Prediction of flashover voltage of non-ceramic insulators under contaminated conditions," IEEE Trans. Dielectr. Electr. Insul, Vol. 13, pp. 862-869, 2006.

[7] Lightning and Insulator Subcommitte, "Application of Insulators in a Contaminated Environment", IEEE Trans. Power App. Syst, Vol. 98, pp. 1676-1695, 1979.

[8] M. Farzaneh and W. A. Chisholm, Insulators for Icing and Polluted Environments, Wiley-IEEE Press, 2009.

[9] IEC 60815, Guide for the selection and dimensioning of high-voltage insulators for polluted conditions - Part 1: Definitions, information and general principles, 2008.

[10] S. Chandrasekar, C. Kalaivanan, G. C. Montanari, and A. Cavallini, "Partial Discharge Detection as a Tool to Infer Pollution Severity of Polymeric Insulators," IEEE Trans. Dielectr. Electr. Insul, Vol. 17, pp. 181-188, 2010.

[11] L. Jingyan, S. Wenxia, S. Caixin, and S. A. Sebo, "Use of leakage currents of insulators to determine the stage characteristics of the flashover process and contamination level prediction", IEEE Trans. Dielectr. Electr. Insul, Vol. 17, pp. 490-501, 2010.

[12] G. Zhicheng, M. Yingke, W. Liming, L. Ruihua, W. Hua, and M. Yi, "Leakage Current and Discharge Phenomenon of Outdoor Insulators", Int'l. J. Electr. Eng. Informatics, Vol. 1, Issue 1, pp. 1$18,2009$.

[13] S. M. Gubanski, A. Dernfalk, J. Andersson, and H. Hillborg, "Diagnostic Methods for Outdoor Polymeric Insulators," IEEE Trans. Dielectr. Electr. Insul, Vol. 14, pp. 1065-1080, 2007.

[14] N. Skou and D. M. L. Vine, Microwave Radiometer Systems: Design and Analysis, Artech House, Incorporated, 2006.

[15] M. Z. Rahman, L. Roytman, and A. H. Kadik, "Refining environmental satellite data using a statistical approach", Proc. SPIE Conf., Sensing Technologies for Global Health, Military Medicine, and Environmental Monitoring III, pp. 87231F-87231F, Baltimore, Maryland, USA, 2013.

[16] R. Acevo-Herrera, A. Aguasca, X. Bosch-Lluis, and A. Camps, "On the use of compact L-band Dicke radiometer (ARIEL) and UAV for 
soil moisture and salinity map retrieval: 2008/2009 field experiments", IEEE Conf. Geoscience and Remote Sensing Symposium (IGARSS), pp. IV-729-IV-732,2009

[17] Y. Lasne, P. Paillou, G. Ruffie, C. Serradilla, F. Demontoux, A. Freeman, T. Farr, K. McDonald, B Chapman and J.-M. Malezieux, "Effect of Salinity on the Dielectric Properties of Geological Materials: Implication for Soil Moisture Detection by Means of Radar Remote Sensing," IEEE Trans. Geosci. Remote Sens., vol. 46, pp. 1674-1688, 2008.

[18] K. A. McColl, D. Ryu, V. Matic, J. P. Walker, J. Costelloe, and C. Rudiger, "Soil Salinity Impacts on L-Band Remote Sensing of Soil Moisture," IEEE Geosci. Remote Sens. Lett., Vol. 9, pp. 262-266, 2012.

[19] IEC 60507, artificial pollution tests on high-voltage insulators to be used on a.c. systems, 1991.

[20] M. C. Dobson, F. T. Ulaby, M. T. Hallikainen, and M. A. El-Rayes, "Microwave Dielectric Behavior of Wet Soil-Part II: Dielectric Mixing Models", IEEE Trans. Geosci. Remote Sens., Vol. GE-23, pp. 35-46, 1985.

[21] A. Stogryn, "Equations for Calculating the Dielectric Constant of Saline Water (Correspondence)", IEEE Trans. Microw. Theory Techn, Vol. 19, pp. 733-736, 1971

[22] J. A. Lane and J. A. Saxton, "Dielectric Dispersion in Pure Polar Liquids at Very High Radio Frequencies. III. The Effect of Electrolytes in Solution", Mathematical Phys. Sci., Vol. 214, pp. 531$545,1952$.

[23] P. K. Weyl, "On the change in electrical conductance of seawater with temperature", Limnology and Oceanography, Vol. 9, pp. 75-78, 1964

[24] Electronic Communications Committee, "The european table of frequency allocations and applications in the frequency range 8.3 khH to $3000 \mathrm{GHz}$, European Conf. Postal and Telecommunications Administrations, pp. 132-133, 2013.

[25] C. Montzka, H. Bogena, T. Jagdhuber, I. Hajnsek, R. Horn, A. Reigber, S. Hasan, C. Rudiger, M. Jaeger and H. Vereecken, "Active and passive L-band microwave remote sensing for soil moisture - A test-bed for SMAP fusion algorithms", IEEE Conf. Geoscience and Remote Sensing Symposium (IGARSS), pp. 2427-2430, 2014.

[26] L. Yujiri, M. Shoucri, and P. Moffa, "Passive millimeter wave imaging," IEEE Microw. Mag., Vol. 4, pp. 39-50, 2003.

[27] K. Sato, H. Kozima, H. Masuzawa, T. Manabe, T. Ihara, Y. Kasashima and K. Yamaki, "Measurements of reflection characteristics and refractive indices of interior construction materials in millimeter-wave bands", IEEE 45 th Conf. in Vehicular Technology, Vol. 1, pp. 449-453, 1995.

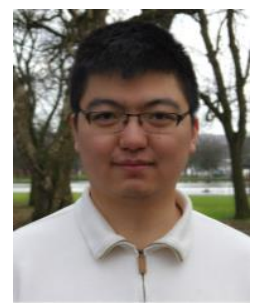

Yan Jiang (M'13) was born in Jiangsu, China. He received the B.Sc. degree from Southeast University in Nanjing, China in 2009, the M.Sc. degree from the University of Manchester, UK in 2011. He is now a Ph.D. student in Glasgow Caledonian University. His research interests focus on the development of novel sensors and condition monitoring system for outdoor insulation.

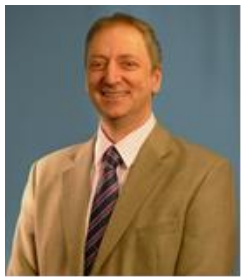

Scott McMeekin is a Professor in the School of Engineering and Built Environment at Glasgow Caledonian University. He received a B.Sc. degree from The University of Strathclyde in 1985 and the M.Sc. and Ph.D. degrees from The University of Glasgow in 1986 and 1989, respectively. Prior to joining Glasgow Caledonian University he was the Process Development manager at Alcatel Optronics Ltd (formerly Kymata Ltd) where he was responsible for the development and qualification of novel optical components for advanced optical telecommunication systems. He has previously worked at the Universities of Cardiff and Glasgow. His current research interests include the development of Instrumentation and Sensor Systems with a specific interest in the condition monitoring of energy assets and the development of photonic bio-sensors. He has published over 110 journal and conferences articles and is co-inventor on 6 patents.

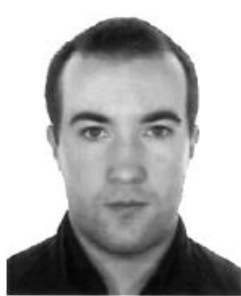

Alistair J. Reid (M'11) graduated from the University of Strathclyde, UK, in 2004 with a B.Eng. (Hons) Degree in electrical and mechanical engineering and received the Ph.D. degree in 2007 for research on partial discharge monitoring. He conducted post-doctoral research within the Institute for Energy and Environment at the University of Strathclyde from 2007-2011, studying advanced radiometric techniques for partial discharge detection and diagnostic monitoring. In 2011 he gained a 2 year Research Fellowship at Glasgow Caledonian University, UK, and in 2013 was awarded a Visiting Research position at California Institute of Technology's Department of Computing and Mathematical Sciences. He is presently a Lecturer within the School of Engineering and Built Environment at Glasgow Caledonian University conducting research on novel condition monitoring systems.

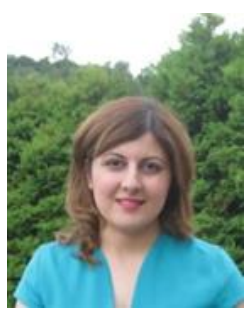

Azam Nekahi received the B.Sc. degree in electrical engineering from the Amirkabir university of technology (Tehran's Polytechnic) in 2004. She obtained the Master and Ph.D. degrees, respectively in 2007 and 2011 at the Université du Québec à Chicoutimi, Canada; within the NSERC/Hydro-Quebec/UQAC Industrial Chair on Atmospheric Icing of Power Network Equipment (CIGELE). Currently Dr. Nekahi is an assistant professor at Glasgow Caledonian University. Her main research interests include outdoor insulation, partial discharge and

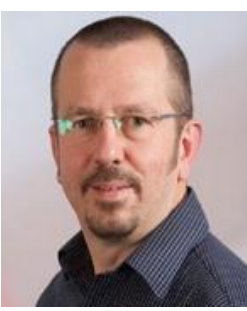
spectroscopy.

Martin D. Judd (M'02-SM'04) is the Technical Director of High Frequency Diagnostics Ltd. He was born in Salford, England in 1963 and graduated from the University of Hull in 1985 with a first class (Hons) degree in electronic engineering, after which he gained 8 years of industrial experience, first with Marconi Electronic Devices and then with EEV Ltd. Martin received his Ph.D. degree from the University of Strathclyde in 1996 for research into the excitation of UHF signals by partial discharges in gas insulated switchgear. He has worked extensively on UHF partial discharge location techniques for power transformers and was latterly Professor of High Voltage Technologies at the University of Strathclyde, where he managed the High Voltage Research Laboratory. In 2014 he founded High Frequency Diagnostics, a contracting and consultancy business that works in partnership with companies and universities to maximize the impact of $R \& D$ outputs by utilizing them in new technologies and applications.

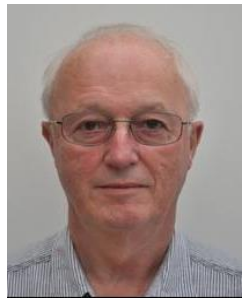

Alan Wilson (B.Sc., Ph.D., C.Eng., FIET). After 35 years working in research and technology areas for UK Utilities, CEGB and National Grid, he worked for a further 15 years for Doble Engineering Co in USA, UK and Germany before retiring in 2015. His utility activities included research in dielectrics, management of transformer and cables technology teams and research programme management. More recent work has included strategy management and responsible for a subsidiary company in Germany. With well over 100 publications he has been active with IET and CIGRE. 